\title{
The impact of hospital and surgeon volume on the 30-day mortality of lung cancer surgery: A nation-based reappraisal
}

\author{
Pierre-Emmanuel Falcoz, MD, PhD, ${ }^{\mathrm{a}}$ Marc Puyraveau, MSc, ${ }^{\mathrm{b}}$ Caroline Rivera, MD, \\ Alain Bernard, MD, PhD, ${ }^{\mathrm{d}}$ Gilbert Massard, MD, PhD, ${ }^{\mathrm{a}}$ Frederic Mauny, MD, $\mathrm{PhD},{ }^{\mathrm{b}}$ \\ Marcel Dahan, $\mathrm{MD}, \mathrm{PhD},{ }^{\mathrm{e}}$ and Pascal-Alexandre Thomas, $\mathrm{MD}, \mathrm{PhD},{ }^{\mathrm{f}}$ on behalf of the Epithor Group
}

\begin{abstract}
Objective: Our objective was to analyze the time trend variation of 30-day mortality after lung cancer surgery, and to quantify the impact of surgeon and hospital volumes over a 5-year period in France.

Methods: We used Epithor, the French national thoracic database and benchmark tool, which catalogues more than 180,000 procedures of 89 private and public hospitals in France. From January 2005 to December 2010 , 19,556 patients who underwent major lung resection (lobectomy, bilobectomy, pneumonectomy) were included in our study. Multilevel logistic models were designed to investigate the relationship between 30-day mortality and surgeon (model 1) or hospital (model 2) volumes. The 3 levels considered were the patient, the surgeon, and the hospital.
\end{abstract}

\begin{abstract}
Results: From 2005 to 2007, the 30-day mortality of patients who underwent major lung resection averaged $10 \%$, and then decreased until it reached $3.8 \%$ in $2010(P<.0001)$. A significant decrease in 30-day mortality was observed over time $(P=.0046)$. During the study period, the mean annual number of procedures per surgeon was 46.1 (standard deviation $[\mathrm{SD}]=23.6)$ and per hospital was $97.9(\mathrm{SD}=50.8)$. Model 1 showed that surgeon volume had a significant impact on 30-day mortality $(P=.03)$, whereas model 2 failed to show that hospital volume influenced 30-day mortality $(P=.75)$.
\end{abstract}

Conclusions: Since 2007, when France's first National Cancer Plan became effective, 30-day mortality of primary lung cancer surgery has decreased and currently measures $3.8 \%$. Low mortality was correlated with higher surgeon volume but was not influenced by hospital volume, which cannot be considered a proxy measure for determining the safety of lung cancer surgery. (J Thorac Cardiovasc Surg 2014;148:841-8)

Different lung cancer resection studies designate hospital and surgeon procedure volumes as easily measurable indicators of surgical quality. ${ }^{1,2}$ However, the reality and soundness of this volume-to-outcome association is still much debated. ${ }^{3}$ Beside serious concerns regarding the statistical methods used to determine this association, ${ }^{4}$ it makes intuitive sense that it should be interpreted cautiously within the framework of a particular health care system.

The French health care organization involves a multiplepayer system with universal coverage (National Health Insurance $[\mathrm{NHI}]$ ), as well as a public-private combination

\footnotetext{
From the Department of Thoracic Surgery, ${ }^{\text {a }}$ Strasbourg University Hospital, Strasbourg; Clinical Methodology Center, ${ }^{\mathrm{b}}$ Besançon University Hospital, Besançon; Department of Thoracic Surgery, ${ }^{c}$ Bayonne Hospital, Bayonne; Department of Thoracic Surgery, ${ }^{\mathrm{d}}$ Dijon University Hospital, Dijon; Department of Thoracic Surgery, ${ }^{\mathrm{e}}$ Toulouse University Hospital, Toulouse; and Department of Thoracic Surgery, ${ }^{\mathrm{f}}$ Marseille University Hospital, Marseille, France.

Disclosures: Authors have nothing to disclose with regard to commercial support.

Read at the 94th Annual Meeting of The American Association for Thoracic Surgery, Toronto, Ontario Canada, April 26-30, 2014.

Received for publication July 22, 2013; revisions received Dec 10, 2013; accepted for publication Jan 21, 2014; available ahead of print Feb 16, 2014.

Address for reprints: Pierre-Emmanuel Falcoz, MD, PhD, Department of Thoracic Surgery, Nouvel Hôpital Civil, Hôpitaux Universitaires de Strasbourg, 1 place de l'Hôpital, BP 426, 67091 Strasbourg Cedex, France (E-mail: pierre-emmanuel. falcoz@wanadoo.fr).

$0022-5223 / \$ 36.00$

Copyright $(2014$ by The American Association for Thoracic Surgery http://dx.doi.org/10.1016/j.jtcvs.2014.01.030
}

of services and hospitals. Patients in France can navigate between both private and public facilities and qualify for reimbursement by the NHI, regardless of which type of facility provides care. Facilities range from small and somewhat isolated hospitals to tertiary referral centers, such as university hospitals and Comprehensive Cancer Centers.

Given the complex and varied cancer care available in France, the government decided to establish quality and safety requirements to guarantee a consistently high level of care. The first National Cancer Plan was launched in 2003 and the French National Cancer Institute (INCa) was created in 2004. This process established a regulatory framework consisting of dedicated facilities, equipment, and services, as well as specific standards for multidisciplinary approaches, best practice guidelines, and the qualification of health professionals. Minimum volume thresholds for radiotherapy, chemotherapy, and cancer surgery were among the requirements on which the accreditation of institutions and structure was based. ${ }^{5}$ For thoracic cancers, the minimum volume threshold was fixed at 30 surgical interventions per year per center, which led to regionalization of cancer surgery services. Subsequently, 257 health care facilities in France ceased to be accredited after 2007 . This represents $65 \%$ of the facilities that previously performed thoracic cancer surgery and about $12 \%$ of the total number of patients treated for a 


\section{Abbreviations and Acronyms \\ FSTCVS $=$ French Society of Thoracic and Cardiovascular Surgery \\ INCa $=$ French National Cancer Institute \\ NHI $=$ National Health Insurance \\ OD $=$ odds ratio \\ $\mathrm{SD} \quad=$ standard deviation}

thoracic malignancy in 2005-2007 in France. Therefore, the French Society of Thoracic and Cardiovascular Surgery (FSTCVS) decided that a timely investigation of the practice procedures of lung cancer surgery, over a period that overlapped with the date on which the legal measures of France's first National Cancer Plan became effective (2007), was necessary.

Thus, the aim of the current study was to explore time trend variation in 30-day mortality after major primary lung cancer surgery, and address and quantify the impact of patient, hospital, and surgeon factors, as well as surgeon and hospital volumes, in a well-defined national context in terms of cancer care facilities and processes.

\section{MATERIALS AND METHODS}

The Institutional Review Board of the FSTCVS approved the electronic prospective database used for this study, as well as the study itself (approval number 2012-1-9-23-6-19-FaPi). Patient consent was obtained before data entry into the database, and patients were aware that data would be used for research purposes.

\section{The French National Database Epithor}

The FSTCVS database, Epithor (http://www.sfctcv.net/pages/epithor. php), was created in 2002 as a voluntary initiative of French thoracic surgeons. Currently, 89 private and public hospitals contribute to this database daily, and it includes data on more than 180,000 procedures, which represents more than $70 \%$ of all thoracic surgical procedures performed in France annually. The database's characteristics have been described in detail previously..$^{6-8}$ All data were analyzed anonymously.

Epithor is a government-approved clinical database funded by INCa for data quality monitoring. Epithor is also approved by the French National High Authority for Health (Haute Autorité de Santé), a governmental agency designed to improve the quality of patient care and to guarantee equity within the health care system. The software includes functions that allow participating surgeons to benchmark their activity against national averages. Regular, external, onsite audits, initiated in 2010, are carried out to verify the accuracy of data collection.

\section{Hospitals and Surgeons}

During the period of data collection, 89 hospitals participated in the Epithor network; 42 were public hospitals (of which 28 were university hospitals) and 47 were for-profit or nonprofit private hospitals. Of the 222 participating surgeons, 160 practiced in public hospitals and 62 were in private practice. As well as thoracic oncology, the whole spectrum of surgical activities offered by the participating hospitals was recorded: 8 centers also performed lung transplantation, 21 performed esophageal surgery, 12 performed trauma surgery, and 30 performed vascular surgery on a regular basis.

\section{Patients}

From January 1, 2005, to December 31, 2010, 122,821 patients were registered in Epithor, of whom 23,753 had received surgery for lung cancer. Of those 23,753 , we selected 20,640 patients who had undergone a major procedure for primary lung cancer: lobectomy $(\mathrm{n}=16,075 ; 77.9 \%)$, bilobectomy $(\mathrm{n}=1166 ; 5.6 \%)$, or pneumonectomy $(\mathrm{n}=3399 ; 16.5 \%)$. Sublobar resections were not taken into consideration because a substantial number had been performed for diagnostic purposes, rather than as potentially curative procedures. Because data entry in certain fields was optional, a mean $3.3 \%$ of values were missing. To enhance the robustness of the results, we excluded those patients for whom less than $95 \%$ of fields had been completed. Therefore, a group of 19,556 adult patients who had undergone a major lung resection for primary lung cancer was selected for further analysis.

\section{Clinical Variables}

Baseline demographics, comorbidities, procedures, and outcomes were recorded. An extra missing value category (referred to as "unknown" in Table 1) was added for the variables with more than $5 \%$ of missing data. For the other variables, missing data were considered as real missing data. The patient-related variables that were used were considered as categorical: age ( $<55,56$ to $65,>65$ years), sex, American Society of Anesthesia score $(\leq 2, \geq 3)$, World Health Organization performance status $(\leq 2$, $\geq 3$, Medical Research Council dyspnea score $(\leq 2, \geq 3)$, and number of comorbid diseases $(0,1-2, \geq 3)$. Surgery-related variables included year of surgery, side of the procedure (left or right), surgical approach (thoracotomy, video-assisted thoracoscopic surgery), lung resection type (lobectomy, bilobectomy, and pneumonectomy), technique of lymphadenectomy (lymphadenectomy, sampling), and admission acuity (elective, emergency/urgent). Pathologic staging in accordance with the American Joint Committee on Cancer Cancer Staging Manual Seventh Edition (stage I, II, or III), histology (adenocarcinoma, squamous cell carcinoma, other), and resection margin status (R0, R1-R2) were also reported. Ninety-five percent of the comorbidities registered in the database were related to 10 major diagnoses: smoking addiction, history of cancer, chronic obstructive pulmonary disease, arterial hypertension, heart disease, diabetes mellitus, peripheral vascular disease, obesity, alcoholism, and hyperlipidemia.

\section{Outcome}

The end point was 30-day mortality, defined as any patient who died within 30 days of the date on which the surgical procedure was performed, regardless of whether the patient was still in hospital or had been discharged. The outcome (30-day individual status) was coded as a binary variable (alive/dead).

\section{Statistical Analysis}

Discrete variables were expressed as counts (\%) and continuous variables were expressed as a mean \pm range, unless otherwise stated. The number of procedures per surgeon (surgeon volume), or per hospital (hospital volume), was defined as the number of surgeries registered in Epithor during the calendar year. For each hospital, the first year of participation in the Epithor database was considered as a training period using the software. Therefore, data that were collected during this period were not used in the analysis. The number of procedures was treated as a quantitative variable. However, the log linearity assumption was relaxed by introducing a third order polynomial function of the entered variables into multivariate models. Time of surgery was also entered.

Multilevel logistic models were designed to investigate the relationship between 30-day mortality and surgeon volume or hospital volume. A trilevel hierarchical structure was considered for analysis: patient, surgeon, hospital. ${ }^{9}$ Variables that were significant at a $P$ value $<.20$ in a bivariate multilevel analysis were introduced into the models. An iterative generalized least squares algorithm was used to run a forward stepwise procedure 
TABLE 1. Baseline patients characteristics $(n=19,556)$

\begin{tabular}{|c|c|c|c|}
\hline Variables & $\begin{array}{l}\text { All patients } \\
(n=19,556)\end{array}$ & $\begin{array}{c}\text { 30-day } \\
\text { mortality } \\
(n=1441) \\
\end{array}$ & $P$ value* \\
\hline Age & & & $<.0001$ \\
\hline$<55 \mathrm{y}$ & 4026 (20.6) & $223(5.5)$ & \\
\hline $55-65 \mathrm{y}$ & $6842(35.0)$ & $410(6.0)$ & \\
\hline$\geq 65 \mathrm{y}$ & $8663(44.4)$ & $808(9.3)$ & \\
\hline Sex & & & $<.0001$ \\
\hline Male & $14,567(74.5)$ & $1233(8.5)$ & \\
\hline Female & $4989(25.5)$ & $208(4.2)$ & \\
\hline Priority of surgery & & & $<.0001$ \\
\hline Elective & $19,443(99,4)$ & $1414(7.3)$ & \\
\hline Urgent/emergency & $113(0.6)$ & 27 (23.9) & \\
\hline ASA score $\dagger$ & & & $<.0001$ \\
\hline$\leq 2$ & $14,126(72.5)$ & $816(5.8)$ & \\
\hline$\geq 3$ & $5362(27.5)$ & 622 (11.6) & \\
\hline Performance status & & & $<.0001$ \\
\hline$\leq 2$ & $17,578(89.9)$ & $1274(7.2)$ & \\
\hline$\geq 3$ & $161(0.8)$ & $36(22.4)$ & \\
\hline Unknown & $1817(9.3)$ & $131(7.2)$ & \\
\hline Dyspnea score & & & $<.0001$ \\
\hline$\leq 2$ & $16,453(84.1)$ & $1184(7.2)$ & \\
\hline$\geq 3$ & 379 (1.9) & $64(16.9)$ & \\
\hline Unknown & $2724(13.9)$ & $193(7.1)$ & \\
\hline Procedure class & & & $<.0001$ \\
\hline Lobectomy & $15,511(79.3)$ & $954(6.1)$ & \\
\hline Bilobectomy & $1064(5.4)$ & $102(9.6)$ & \\
\hline Pneumonectomy & $2981(15.2)$ & 385 (12.9) & \\
\hline Surgical approach & & & .0906 \\
\hline Thoracotomy & $19,120(97.8)$ & $1418(7.4)$ & \\
\hline VATS & $436(2.2)$ & $23(5.3)$ & \\
\hline Side & & & .0295 \\
\hline Right & $11,184(57.5)$ & $863(60.2)$ & \\
\hline Left & $8271(42.5)$ & $570(39.8)$ & \\
\hline Lymph node dissection $†$ & & & $<.0001$ \\
\hline Lymphadenectomy & $17,922(93.9)$ & $1246(6.9)$ & \\
\hline Systematic sampling & $1175(6.1)$ & 134 (11.4) & \\
\hline Tumor histology§ & & & $<.0001$ \\
\hline Adenocarcinoma & 8992 (49.8) & $571(6.4)$ & \\
\hline Squamous cell carcinoma & $6026(33.4)$ & $593(9.8)$ & \\
\hline Other & $3024(16.8)$ & $186(6.1)$ & \\
\hline Pathologic stage & & & $<.0001$ \\
\hline IA or IB & 8747 (44.7) & $433(4.9)$ & \\
\hline IIA or IIB & $3138(16.1)$ & $241(7.7)$ & \\
\hline IIIA or IIIB & $5031(25.7)$ & $594(11.8)$ & \\
\hline Unknown & $2640(13.5)$ & $173(6.5)$ & \\
\hline Resection margin status $\|$ & & & $<.0001$ \\
\hline R0 & $17,256(96.5)$ & $1252(7.3)$ & \\
\hline R1-R2 & $618(3.5)$ & $85(13.7)$ & \\
\hline Comorbidities $\uparrow$ & & & $<.0001$ \\
\hline None & $2215(11.3)$ & $80(3.6)$ & \\
\hline $1-2$ & $9088(46.5)$ & $568(6.2)$ & \\
\hline$\geq 3$ & $8252(42.2)$ & 793 (9.6) & \\
\hline Year of surgery & & & $<.0001$ \\
\hline 2005 & $2539(13.0)$ & 298 (11.7) & \\
\hline 2006 & 2706 (13.8) & $230(8.5)$ & \\
\hline
\end{tabular}

TABLE 1. Continued

\begin{tabular}{lrcc}
\hline & $\begin{array}{c}\text { 30-day } \\
\text { All patients } \\
\text { Variables }\end{array}$ & $\begin{array}{c}\text { mortality } \\
(\mathbf{n}=\mathbf{1 9 , 5 5 6})\end{array}$ & $\boldsymbol{P}$ value* \\
\hline 2007 & $3101(15.9)$ & $289(9.3)$ & \\
2008 & $3452(17.7)$ & $255(7.4)$ & \\
2009 & $4074(20.8)$ & $227(5.6)$ & \\
2010 & $3684(18.8)$ & $142(3.8)$ & \\
Type of hospital & & & $<.034$ \\
Public & $14,292(73.1)$ & $956(6.7)$ & \\
Private & $5264(26.9)$ & $485(9.2)$ & \\
\hline
\end{tabular}

Data are expressed as numbers and percentages of patients. Because of rounding, percentages may not sum to 100 . Because of missing data, the regression analysis included 19,462 patients. ASA, American society of Anesthesiologists; VATS, video-assisted thoracoscopic surgery. *Multilevel comparison between 30-day dead or alive status of patients. $\dagger 68$ missing data. $\ddagger 459$ missing data. $\S 1514$ missing data. $\| 1682$ missing data. $\$ 1$ missing data.

within each level. An equivalent Bayesian model was then created by incorporating prior distributions for each of the parameters in the model, and performing inference on the resulting posterior distributions. A burn-in of 5000 iterations was allowed, followed by 100,000 iterations for which parameter values were stored. The diagnosis (based on chain history, kernel density plots, and plots of autocorrelation and partial autocorrelation function) gave no indication that lack of convergence should be suspected. The odd ratios (ORs) and their $95 \%$ confidence intervals were calculated. For the number of surgeries, the results are expressed as for an increase of 10 procedures. The discriminatory accuracy of the models was quantified using the $\mathrm{C}$ statistic, which provides an estimate of the model's ability to discriminate between observed instances of 30-day mortality and survival. ${ }^{10} \mathrm{~A}$ value of 0.5 indicates that the model does not demonstrate any predictive discrimination, whereas a value of 1 indicates perfect separation. Multilevel analysis was performed using MLwiN V2.23 software. ${ }^{11}$ All other statistical analyses were performed with SAS 9.3 software (SAS Institute Inc., Cary, NC).

\section{RESULTS}

The baseline patient characteristics and 30-day mortality are given in Table 1. During the 6 years of the study period, there were 1441 deaths $(7.4 \%)$ among the cohort. The observed 30-day mortality averaged $10 \%$ until 2007 , and then decreased continuously until it reached $3.8 \%$ in $2010(P<.0001)$ (Table 1$)$. There were 956 deaths $(6.7 \%)$ in public hospitals and $485(9.2 \%)$ in private hospitals $(P<.034)$. The 30 -day mortality did not statistically differ when comparing participating centers with regard to additional surgical activities such as lung transplantation (7.0\% vs $8.4 \%, P=.84)$, trauma $(7.5 \%$ vs $7.0 \%, P=.64)$, esophageal $(7.6 \%$ vs $6.8 \%, P=.71)$, or vascular $(7.6 \%$ vs $4.8 \%, P=.051)$ surgeries. The mean annual number of procedures per hospital was 97.9 (standard deviation $[\mathrm{SD}]=50.8)$, with minimum, median, and maximum values of 1,93 , and 224 , respectively. The mean annual number of procedures was $113.7(\mathrm{SD}=48.4)$ in public hospitals and 55.0 $(\mathrm{SD}=26.9)$ in private hospitals $(P<.0001)$. On average, a patient is operated on by a surgeon who, within a year, operated on $46.1(\mathrm{SD}=23.6)$ patients, with 
minimum, median, and maximum values of 1,47 , and 106 , respectively. For surgeons working in public hospitals, the mean annual number of procedures was 46.7 $(\mathrm{SD}=24.2)$; it was $44.3(\mathrm{SD}=21.9)$ for surgeons working in private hospitals $(P<.0001)$. Thirteen hospitals $(14.6 \%)$ and 30 surgeons $(13.5 \%)$ performed $50 \%$ of the total number of procedures in France, and $12.6 \%$ of surgeons performed at least 46 procedures per year.

The results of the multilevel logistic regression analysis are summarized in Table 2. Model 1 highlights 30-day mortality, taking into account annual surgeon volume. Model 2 highlights 30-day mortality, taking into account annual hospital volume. The variables related to patients, type of hospital, and time trends were almost identical for the 2 models. The $\mathrm{C}$ statistic obtained for the 2 models was 0.81 . Model 1 showed that surgeon volume had a significant impact on 30-day mortality $(P=.03)$, whereas model 2 showed that hospital volume did not have any impact on 30-day mortality $(P=.75)$.

Model 1 showed that 30-day mortality was strongly influenced by pneumonectomy ( $\mathrm{OR}=2.01$ ), pathologic stage III $(\mathrm{OR}=2.24)$, and the number of comorbidities greater than $3(\mathrm{OR}=2.51)$. Model 1 also showed that there was a higher risk of mortality in private hospitals $(\mathrm{OR}=1.65 ; P=.0170)$ than in public hospitals. The results indicated a significant decrease in 30-day mortality over time $(P=.0046)$ during the study period (Figure 1). The significant interaction between type of hospital and time trends indicated that the ORs associated with the decrease of 30-day mortality over time were higher in private hospitals than in public hospitals ( $\mathrm{OR}=0.85 ; P=.0343)$. Figure 2 presents the variations in ORs on 30-day mortality over time by surgeon volume or hospital volume. Figure 2 does not show a statistically significant variation for hospital volume. On the contrary, it does show a statistically significant variation for surgeon volume.

\section{DISCUSSION}

This study provides the most current appraisal of 30-day mortality after primary lung cancer surgery in France. To date, few studies have had the opportunity to undertake this kind of investigation from a comprehensive, nationwide, population-based dataset. Our study showed that during the period 2005-2010, the average 30-day mortality for patients who had undergone major pulmonary resection was $7.4 \%$. This rate is much higher than that reported for the same period by the United Kingdom's second National Thoracic Surgery Activity \& Outcomes Report (2.4\%). ${ }^{12}$ It is also higher than the rate reported for the period 20032009 by a US database that assembles the data of $20 \%$ of all hospital discharges from nonfederal facilities $(3.4 \%) .{ }^{13}$ Since 2007 , 30-day mortality has decreased continuously in France and in 2010 the value was 3.8\%, reaching the international standards discussed previously.
This rate converged in all types of hospitals. The improvement in surgical safety that the present study highlights is unlikely to be a major consequence of the centralization of thoracic oncologic surgeries in France. Although 257 health care facilities ceased to be accredited after 2007, only 6 centers participating in Epithor failed to reach the minimal threshold of activity and were closed during the study period. Furthermore, because the redeployment rate of thoracic surgical activities was $10 \%$ to $15 \%$ overall, it had a negligible impact on mortality.

Our study clearly shows that, in the context of the French health care system, hospital volume is not a proxy measure for determining the safety of lung cancer surgery. The volume-outcome relationship is extremely complex. As suggested by Royston and colleagues, ${ }^{14}$ procedure volume was first represented as a continuous variable, rather than being converted into arbitrarily determined categories that amplify the impact of volume on risk of mortality when measured by ORs. The cut-off value of the highest volume strata in one study may be lower than another study's lowest hospital volume strata cut-off. ${ }^{15}$ To describe the nonlinearity present in the volume-outcome relationship, a regression function was modeled as a piecewise polynomial that produced a representation of the volume-outcome association. A hierarchical, multilevel modeling technique was used; hospitals and surgeons were considered/incorporated as random effects, which adjusted for potentially overdispersed variance estimates. ${ }^{16}$ The database that was used was dedicated to clinical specialty and capable of understanding and weighting the clinical significance of the statistical relationship between volume and mortality. ${ }^{4}$ The chosen model was excellent because, with its $\mathrm{C}$ statistic of 0.81 , it was able to discriminate between observed instances of 30-day death and survival.

Our findings are consistent with those of Birkmeyer and colleagues ${ }^{17}$ who established that the observed association between hospital volume and operative mortality was largely mediated by surgeon volume. Our findings are also fully in line with those of Lien and colleagues, ${ }^{18}$ who showed that an inverse volume-outcome relationship exists for surgeons, but not for hospitals. Having defined volume categories by tertiles, Lien and colleagues found a significantly higher mortality for surgeons who performed less than 46 procedures per year. Our current study also shows that better results were obtained for surgeons with an annual volume of more than 46 procedures $(\mathrm{OR}<1)$ (Figure 2). This similarity is likely to be coincidental because only major procedures were considered in our study, whereas sublobar resections were also taken into account by Lien and colleagues. ${ }^{18}$ A meta-analysis of Birkmeyer and Lien's studies showed a pooled estimated effect size in favor of high-volume surgeons. However, this effect did not have statistical significance and was very heterogeneous. ${ }^{15}$ In 2 other studies, in-hospital mortality after lobectomy was not significantly related to the number of procedures performed by 
TABLE 2. Multivariate analysis determinants of 30-day mortality after major lung cancer surgery

\begin{tabular}{|c|c|c|c|c|}
\hline \multirow[b]{3}{*}{ Variables } & \multicolumn{2}{|l|}{ Model 1} & \multicolumn{2}{|c|}{ Model 2} \\
\hline & \multicolumn{2}{|c|}{ Surgeon level activity } & \multicolumn{2}{|c|}{ Hospital level activity } \\
\hline & OR $[95 \% \mathrm{CI}]$ & $P$ value & OR $[95 \% \mathrm{CI}]$ & $P$ value \\
\hline Age & & $<.0001$ & & $<.0001$ \\
\hline$<55 \mathrm{y}$ & 1 & & 1 & \\
\hline $55-65$ y & $0.95[0.79-1.14]$ & & $0.95[0.79-1.14]$ & \\
\hline$\geq 65 \mathrm{y}$ & $1.53[1.30-1.82]$ & & $1.53[1.30-1.82]$ & \\
\hline Sex & & $<.0001$ & & $<.0001$ \\
\hline Male & 1 & & 1 & \\
\hline Female & $0.63[0.53-0.74]$ & & $0.63[0.54-0.74]$ & \\
\hline Priority of surgery & & .0516 & & .0516 \\
\hline Elective & 1 & & 1 & \\
\hline Urgent/emergency & $1.69[0.99-2.86]$ & & $1.69[0.99-2.86]$ & \\
\hline ASA score & & $<.0001$ & & $<.0001$ \\
\hline$\leq 2$ & 1 & & 1 & \\
\hline$\geq 3$ & $1.73[1.52-1.97]$ & & $1.73[1.51-1.98]$ & \\
\hline Performance status & & .0095 & & .0090 \\
\hline$\leq 2$ & 1 & & 1 & \\
\hline$\geq 3$ & $2.02[1.29-3.18]$ & & $2.02[1.29-3.16]$ & \\
\hline Unknown & $1.03[0.73-1.47]$ & & $1.06[0.74-1.50]$ & \\
\hline Dyspnea score & & .0030 & & .0016 \\
\hline$\leq 2$ & 1 & & 1 & \\
\hline$\geq 3$ & $1.50[1.08-2.09]$ & & $1.50[1.08-2.09]$ & \\
\hline Unknown & $0.70[0.51-0.96]$ & & $0.67[0.49-0.92]$ & \\
\hline Procedure class & & $<.0001$ & & $<.0001$ \\
\hline Lobectomy & 1 & & 1 & \\
\hline Bilobectomy & $1.48[1.17-1.87]$ & & $1.49[1.17-1.88]$ & \\
\hline Pneumonectomy & $2.01[1.74-2.33]$ & & $2.01[1.74-2.33]$ & \\
\hline Pathologic stage & & $<.0001$ & & $<.0001$ \\
\hline IA or IB & 1 & & 1 & \\
\hline IIA or IIB & $1.33[1.11-1.58]$ & & $1.32[1.11-1.58]$ & \\
\hline IIIA or IIIB & $2.24[1.94-2.60]$ & & $2.24[1.93-2.59]$ & \\
\hline Unknown & $1.79[1.44-2.22]$ & & $1.79[1.44-2.22]$ & \\
\hline Comorbidities & & $<.0001$ & & $<.0001$ \\
\hline None & 1 & & 1 & \\
\hline $1-2$ & $1.65[1.28-2.13]$ & & $1.67[1.28-2.17]$ & \\
\hline$\geq 3$ & $2.51[1.93-3.27]$ & & $2.54[1.94-3.33]$ & \\
\hline Type of hospital & & .0170 & & .0206 \\
\hline Public & 1 & & 1 & \\
\hline Private & $1.65[1.10-2.49]$ & & $1.65[1.08-2.52]$ & \\
\hline Time trends & $0.88[0.80-0.96]$ & .0046 & $0.88[0.80-0.96]$ & .0063 \\
\hline Interaction type of hospital/time trends & $0.85[0.73-0.99]$ & .0343 & $0.86[0.74-0.99]$ & .0424 \\
\hline Proc 1 & $0.92[0.85-0.99]$ & .0323 & $0.99[0.94-1.04]$ & .7488 \\
\hline Proc 2 & 0.9985 [0.9970-0.9999] & .0414 & $0.9999[0.9995-1.0004]$ & .9735 \\
\hline Proc 3 & $1.00004[1.0000008-1.0000792]$ & .08694 & $1[1-1]$ & .5028 \\
\hline
\end{tabular}

surgeons. ${ }^{19,20}$ In contrast, our study supports the hypothesis that the decline in operative mortality is in part due to increasing surgeon dedication to lung cancer surgery within hospitals, and even teams. There was an inverse relationship between surgeon volume and mortality, but no significant beneficial influence for the regular practice of other high-risk surgeries. Moreover, it would be unrealistic to expect lung cancer resections to be primarily undertaken by $10 \%$ to $15 \%$ of the thoracic surgeons currently active in France. Such an increased workload would have an inverse effect on surgical safety, as recently suggested by a retrospective study from the Mayo Clinic. ${ }^{21}$

Our study strongly suggests that outcomes measured with feedback programs, self-assessment capabilities, and benchmark tools, such as those provided by the Epithor software, are probably more effective than volume-based 


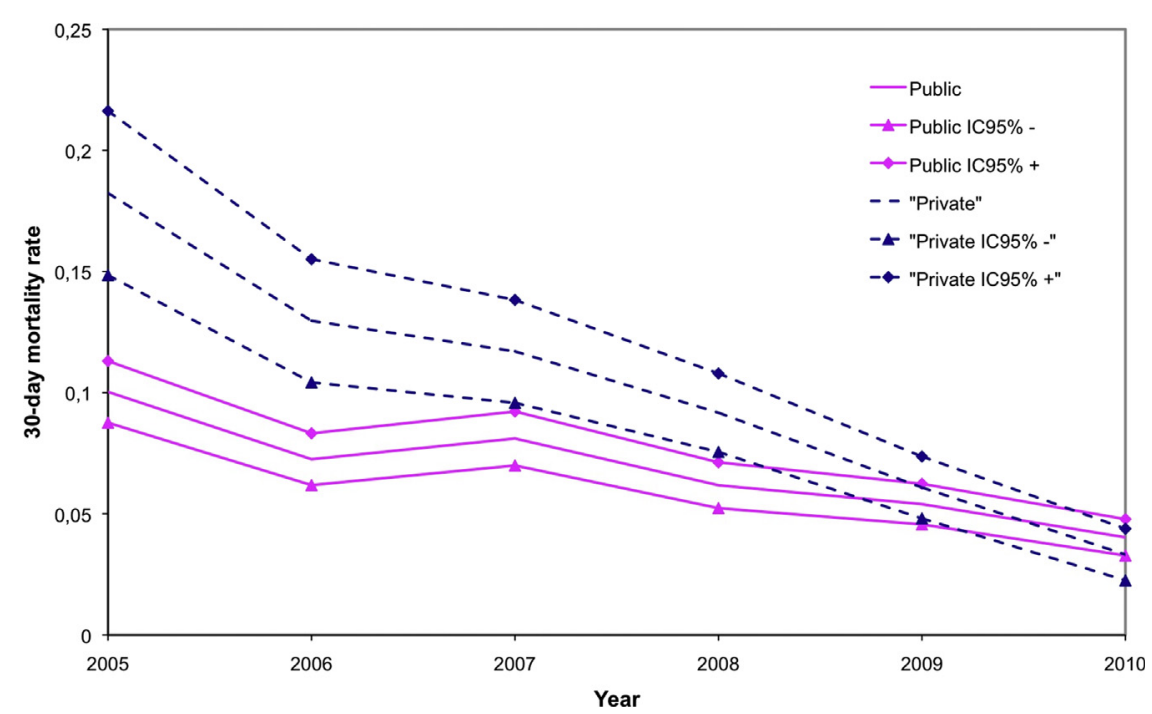

FIGURE 1. Time trends in observed 30-day mortality: public and private hospitals. Over time, we note a decrease in 30-day mortality both in public and private hospitals with a more significant improvement in the private sector. IC $95 \%, 95 \%$ confidence interval.

referral policies for improving surgical safety. We showed that the longer a given hospital or surgeon participates in Epithor, the better the outcome. Because their initial results were significantly worse than those of the public hospitals, the improvement in surgical safety was particularly spectacular for the private hospitals, which by 2010 had reached the national average values for 30-day mortality. Various public and private US hospitals have already reported the virtuous process by which a dramatic decline in the rate of postoperative adverse events and 30-day mortality was observed after the adoption of a National Surgical Quality Improvement Program. ${ }^{22}$ The Hawthorne effect, which establishes that the feeling of being observed, or merely participating in an experiment, can affect individuals' behavior, might also be a possible explanation for the improvement in results. $^{23}$

There are limitations to our study. Since 2008, after the application of the legal measures of the National Cancer Plan, only centers performing more than 30 procedures per year participated in Epithor, thus decreasing the ability to find an outcome effect of hospital volume on mortality. Our study focused on 30-day mortality, which is an imperfect surrogate for the risk of mortality attributable to surgery. Treatment-related mortality should preferably

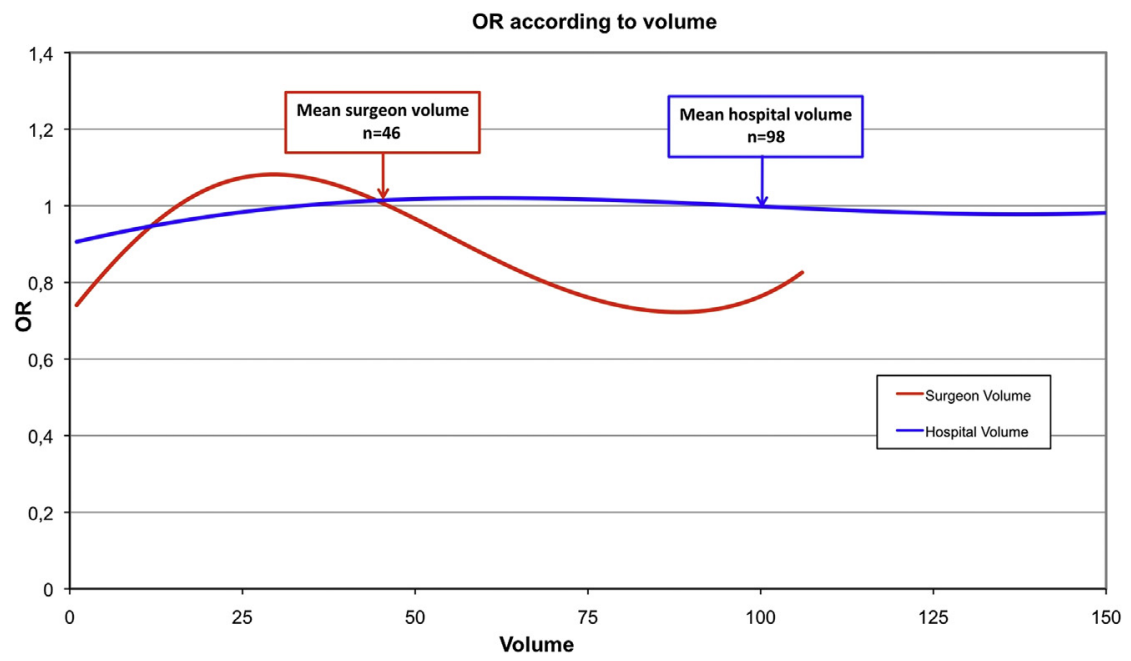

FIGURE 2. Variations in odd ratios $(O R)$ on 30-day mortality by surgeon or hospital volume. The blue curve symbolizes the modelized odds variation by hospital volume for 30-day mortality within the Epithor database. The red curve symbolizes the odds variation by surgeon volume for 30-day mortality within the Epithor database. The reference value is 46 procedures per year by surgeon $(\mathrm{OR}=1)$ corresponding to the mean number of procedures done by a given surgeon within Epithor. The lowest $\mathrm{OR}$ is estimated for 89 procedures by year $(\mathrm{OR}=0.722)$, whereas the highest $\mathrm{OR}$ is estimated for 30 major procedures per year $(\mathrm{OR}=1.081)$. 
include all deaths that occur as a consequence of a procedure, regardless of the time span between the procedure and death. For instance, 90 -day mortality ${ }^{24}$ or 6-month mortality $^{25}$ has been used for pneumonectomy, after which physiologic cardiopulmonary impairment due to surgery can lead to late deaths. Moreover, mortality does not sum up safety. The overall risk of complications and failure to rescue (defined as mortality after a complication) are additional outcomes of interest. ${ }^{13}$ Safety does not mean quality, even if these 2 factors are correlatively related. Long-term survival and resection rate are the primaries objectives of surgery when analyzed as a potentially curative treatment in a population-based assessment. ${ }^{26}$

\section{CONCLUSIONS}

Our findings highlight the overall efficiency of France's first National Cancer Plan, implemented in 2007, and its legal requirements for the practice of surgical oncology. Encouraging participation in a systematic clinical database registry is 1 of the key measures of this plan, which was well anticipated by the FSTCVS and the Epithor project. Epithor stores the best available data (clinical, risk-adjusted and case mix-adjusted, nationally benchmarked and audited 30-day patient outcomes) and provides a more accurate look at surgical safety than measures based solely on a volume-outcome relationship. Referring patients, primarily or solely, to surgeons who perform a large number of procedures should not be advocated because of a possible inverse effect on surgical safety. Nevertheless, it only makes good sense that low-volume surgeons with a high observed/expected mortality ratio should scrutinize their practice procedures and benchmark their results against national averages that include high-volume surgeons with good outcomes. They may make improvements in safety, and as a result of this, learn from mistakes.

The authors would like to thank Lindsey Cosby for her expert editorial review of the manuscript. We are grateful to all the French thoracic surgeons who participated in this study for their essential collaboration: Dr M. Alauzen (Montpellier), Dr J.F. Andro (Quimper), Dr M. Aubert (Grenoble), Dr J.P. Avaro (Marseille), Professor J. Azorin (Bobigny), Dr P. Bagan (Argenteuil), Dr F. Bellenot (Cergy-Pontoise), Dr V. Blin (Vannes), Dr P. Boitet (Harfleur), Dr L. Bordigoni (Toulon), Professor J. Borrelly (Nancy), Professor P.Y. Brichon (Grenoble), Dr G. Cardot (Boulogne-surMer), Dr J.M. Carrie (Saint-Jean), Dr F. Clement (Besançon), Professor P. Corbi (Poitiers), Dr M. Debaert (Lille), Dr B. Debrueres (Ploemeur), Dr J. Dubrez (Bayonne), Dr X. Ducrocq (Strasbourg), Dr A. Dujon (Bois-Guillaume), Professor P. Dumont (Tours), Dr P. Fernoux (Chalon-sur-Saône), Professor M. Filaire (Clermont-Ferrand), Dr E. Frassinetti (Chambéry), Dr G. Frey (Saint-Etienne), Dr D. Gossot (Paris), Professor G. Grosdidier (Nancy), Dr B. Guibert (Lyon), Dr O. Hagry (Chalon-sur-Saône), Dr S. Jaillard (Lille), Dr J.M. Jarry (Aix en Provence), Dr D. Kaczmarek (Saint-Etienne), Dr Y. Laborde (Pau), Dr B. Lenot (Saint-Brieuc),
Dr F. Levy (Bordeaux), Dr L. Lombart (Béziers), Dr E. Marcade (Saint-Grégoire), Dr J.P. Marcade (La Rochelle), Dr J. Marzelle (Créteil), Dr F. Mazeres (Bayonne), Dr E. Mensier (Lille), Dr D. Metois (Orléans), Dr J.L. Michaud/E. Paris (Nantes), Dr P. Mondine (Brest), Dr M. Monteau (Reims), Dr J.M. Moreau (Nantes), Professor J. Mouroux (Nice), Dr A. Mugniot (Nantes), Dr P. Mulsant (Lyon), Dr N. Naffaa (Avignon), Dr P. Neveu (Talant), Dr G. Pavy (Arras), Professor C. Peillon (Rouen), Professor F. Pons (Percy), Professor H. Porte (Lille), Professor J.F. Regnard (Paris), Professor M. Riquet (Paris), Dr B. Sadeghi Looyeh (Morlaix), Dr N. Santelmo (Strasbourg), Professor O. Tiffet (Saint-Etienne), Dr B. Tremblay (Meaux), Dr J. Valla (Charenton le Pont), Professor J.F. Velly (Pessac), Dr B. Wack (Metz), Dr J.D. Wagner (Colmar), Dr D. Woelffe (Valenciennes).

\section{References}

1. Bach PB, Cramer LD, Schrag D, Downey RJ, Gelfand SE, Begg CB. The influence of hospital volume on survival after resection for lung cancer. $N$ Engl J Med. 2001;345:181-8

2. Birkmeyer JD, Siewers AE, Finlayson EV, Stukel TA, Lucas FL, Batista I, et al. Hospital volume and surgical mortality in the united states. N Engl J Med. 2002; 346:1128-37.

3. Kozower BD, Stukenborg GJ. Lung cancer resection volume: is procedure volume really an indicator of quality? Semin Thoracic Surg. 2012;24:93-8.

4. Livingston EH, Cao J. Procedure volume as a predictor of surgical outcomes. JAMA. 2012;304:95-7.

5. Evrard S. Enhancing patient safety and quality of surgical cancer care: the French National Cancer plans. Eur J Surg Oncol. 2010;36:S14-7.

6. Falcoz PE, Conti M, Brouchet L, Chocron S, Puyraveau M, Mercier M, et al. The Thoracic Surgery Scoring System (Thoracoscore): risk model for in-hospital death in 15,183 patients requiring thoracic surgery. J Thorac Cardiovasc Surg. 2007; 133:325-32.

7. Bernard A, Rivera C, Pages PB, Falcoz PE, Vicaut E, Dahan M. Risk model of inhospital mortality after pulmonary resection for cancer: a national database of the French Society of Thoracic and Cardiovascular Surgery (Epithor). J Thorac Car diovasc Surg. 2011;141:449-58

8. Rivera C, Falcoz PE, Bernard A, Thomas PA, Dahan M. Surgical management and outcomes of elderly patients with early stage non-small cell lung cancer: a nested case-control study. Chest. 2011;140:874-80.

9. Goldstein H. Multilevel Statistical Models. 2nd edition. London: Edward Arnold; 1995:1-178.

10. Harrell FE Jr, Califf RM, Pryor DB, Lee KL, Rosati RA. Evaluating the yield of medical tests. JAMA. 1982;247:2543-6.

11. Browne WJ. MCMC Estimation in MLwiN v2.1. Centre for Multilevel Modeling, University of Bristol; 2009

12. The Society for Cardiothoracic Surgery in Great Britain \& Ireland. Second National Thoracic Surgery Activity \& Outcomes Report 2011. Available at: http://www.scts.org/_userfiles/resources/634558869917493937_Thoracic_2011_ FINAL.pdf. Accessed December 29, 2012.

13. Bhamidipati CM, Stukenborg GJ, Ailawadi G, Lau CL, Kozower BD Jones DR. Pulmonary resections performed at hospitals with thoracic surgery residency programs have superior outcomes. J Thorac Cardiovasc Surg. 2013;145:60-7.

14. Royston P, Altman DG, Sauerbrei W. Dichotomizing continuous predictors in multiple regression: a bad idea. Stat Med. 2006;25:127-41.

15. von Meyenfeldt EM, Gooiker GA, van Gijn W, Post PN, van de Velde CJ, Tollenaar RA, et al. The relationship between volume or surgeon specialty and outcome in the surgical treatment of lung cancer: a systematic review and meta-analysis. J Thorac Oncol. 2012;7:1170-8.

16. Panageas KS, Schrag D, Riedel E, Bach PB, Begg CB. The effect of clustering of outcomes on the association of procedure volume and surgical outcomes. Ann Intern Med. 2003;139:658-65.

17. Birkmeyer JD, Stukel TA, Siewers AE, Goodney PP, Wennberg DE, Lucas FL. Surgeon volume and operative mortality in the United States. $N$ Engl J Med. 2003;349:2117-27.

18. Lien YC, Huang MT, Lin HC. Association between surgeon and hospital volume and in-hospital fatalities after lung cancer resections: the experience of an Asian country. Ann Thorac Surg. 2007;83:1837-43. 
19. Hannan EL, Radzyner M, Rubin D, Dougherty J, Brennan MF. The influence of hospital and surgeon volume on in-hospital mortality for colectomy, gastrectomy, and lung lobectomy with cancer. Surgery. 2002;131:6-15.

20. Treasure T, Utley M, Bailey A. Assessment of whether in-hospital mortality for lobectomy is useful standard for the quality of lung cancer surgery: retrospective study. BMJ. 2003;327:73-5.

21. Thomas M, Allen MS, Wigle DA, Shen KR, Cassivi SD, Nichols FC 3rd, et al. Does surgeon workload per day affect outcomes after pulmonary lobectomies? Ann Thorac Surg. 2012;94:966-72.

22. Khuri SF, Henderson WG, Daley J, Jonasson O, Jones RS, Campbell DA Jr, et al; Principal Investigators of the Patient Safety in Surgery Study. Successful implementation of the Department of Veterans Affairs' National Surgical Quality Improvement Program in the private sector: the Patient Safety in Surgery study. Ann Surg. 2008;248:329-36.

23. Wickström G, Bendix T. The "Hawthorne effect" - what did the original Hawthorne studies actually show? Scand J Work Environ Health. 2000;26:363-7.

24. Doddoli C, Barlesi F, Trousse D, Robitail S, Yena S, Astoul P, et al. One hundred consecutive pneumonectomies after induction therapy for non-small cell lung cancer: an uncertain balance between risks and benefits. J Thorac Cardiovasc Surg. 2005;130:416-25.

25. Rodríguez M, Gómez MT, Jiménez MF, Aranda JL, Novoa N, Varela G. The risk of death due to cardiorespiratory causes increases with time after right pneumonectomy: a propensity score-matched analysis. Eur J Cardiothorac Surg. 2013; 44:93-7.

26. Thorsteinsson H, Alexandersson A, Oskarsdottir GN, Skuladottir R, Isaksson HJ, Jonsson S, et al. Resection rate and outcome of pulmonary resections for nonsmall-cell lung cancer: a nationwide study from Iceland. J Thorac Oncol. 2012;7:1164-9.

\section{Discussion}

Dr Ara Vaporciyan (Houston, Tex). Dr Falcoz and his colleagues have leveraged a new modern multi-institutional database to examine the impact of the National Cancer Plan on outcomesspecifically mortality-associated with the treatment of lung cancer.

I actually sent Dr Falcoz my questions ahead of time and he actually already answered 2 out of the 3 , so in the interest of letting the crowd have an opportunity to ask a question, I'm going to go right to the third question.

I suspect that it is hard, as you identified, to dissect the impact of a new database and the Hawthorne effect from the impact of a new National Cancer Plan. However, considering the health care environment in the United States, I would imagine that many of us in this audience are very interested in any evidence that demonstrates the true value of a national health care plan or any sort of nationalization of care. Therefore, this question really focuses on what you are going to do next. As the new National Cancer Plan in France gains traction, how are you going to truly examine the impact of that plan on the delivery of care?

Dr Falcoz. Thank you for your final question, Dr Vaporciyan.

It might be a little bit difficult to answer, because, as you said, it is a challenge to highlight the individual contribution of the database from the National Cancer Plan, especially as the participation in our database is a mandatory requirement as one of the measures of the cancer plan. So it is difficult to dissect between the two contributions because one is mandatory. Clearly, the legal measure of the cancer plan for a given department means that you belong to a database. To conclude, I don't think it will be possible to clearly give you an answer of who does what. The effects are mixed.

\section{COMMENTARY}

\section{Editorial comment}

\section{Benjamin D. Kozower, MD, MPH}

The volume-outcome relationship has been used as a proxy measure for quality for more than 3 decades since first proposed by Luft and colleagues ${ }^{1}$ in 1979 . In this issue of the Journal of Thoracic and Cardiovascular Surgery, Falcoz and colleagues ${ }^{2}$ report the results of lung cancer resection

From the Department of General Thoracic Surgery, University of Virginia, Charlottesville, Va.

Disclosures: Author has nothing to disclose with regard to commercial support.

Received for publication Feb 12, 2014; accepted for publication Feb 14, 2014; available ahead of print March 28, 2014.

Address for reprints: Benjamin D. Kozower, MD, MPH, University of Virginia, General Thoracic Surgery, PO Box 800679 (E-mail: BDK8G@hscmail.mcc.virginia. edu).

J Thorac Cardiovasc Surg 2014;148:848-9

$0022-5223 / \$ 36.00$

Copyright (c) 2014 by The American Association for Thoracic Surgery

http://dx.doi.org/10.1016/j.jtcvs.2014.02.042 in France captured in the Epithor database. From 2005 to 2010, the database captured the data for almost 20,000 patients undergoing anatomic lung resection for lung cancer. The most striking result of their report was the decrease in 30-day mortality from $10 \%$ in 2005 to $3.8 \%$ in 2010 .

The authors used sophisticated hierarchical logistic regression models to evaluate the relationship between procedure volume (both surgeon and hospital) and 30-day mortality. Rather than categorizing the procedure volume into arbitrary groups such as quartiles or quintiles, the authors appropriately modeled volume as a continuous variable using a polynomial function. The results have demonstrated that surgeon volume, but not hospital volume, was associated with 30-day mortality, with a $P$ value $<.05$. Although this is statistically significant, it is unclear how 